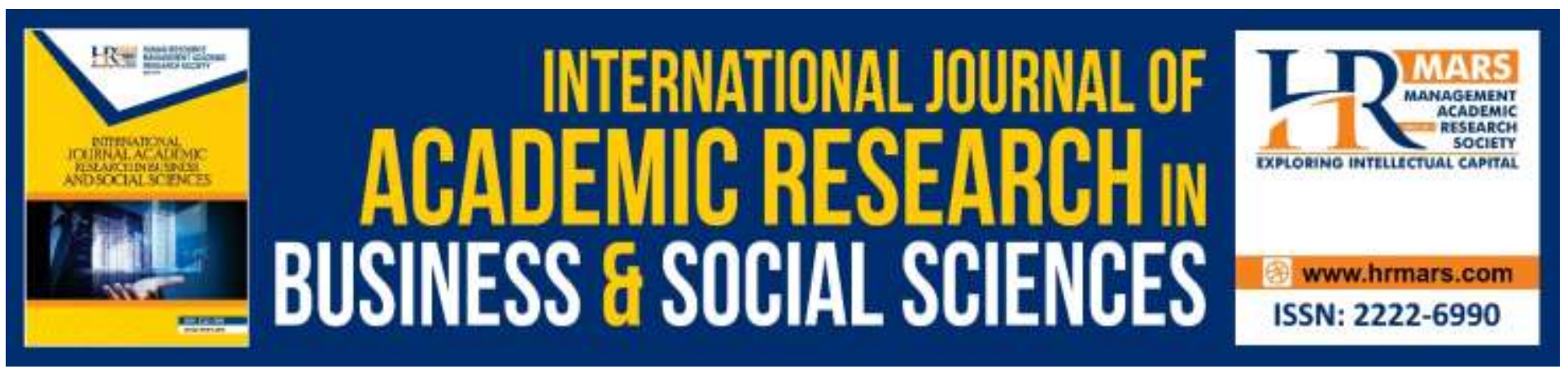

\title{
Elements of Gastronomy Tourism Affecting the Behavior of Thai Tourists Traveling in Thailand
}

\section{Puri Chunkajorn}

To Link this Article: http://dx.doi.org/10.6007/IJARBSS/v10-i2/6938

DOI:10.6007/IJARBSS/v10-i2/6938

Received: 03 January 2020, Revised: 28 January 2020, Accepted: 02 February 2020

Published Online: 21 February 2020

In-Text Citation: (Chunkajorn, 2020)

To Cite this Article: Chunkajorn, P. (2020). Elements of Gastronomy Tourism Affecting the Behavior of Thai Tourists Traveling in Thailand. International Journal of Academic Research in Business and Social Sciences, 10(2), 401-411.

Copyright: (C) 2020 The Author(s)

Published by Human Resource Management Academic Research Society (www.hrmars.com)

This article is published under the Creative Commons Attribution (CC BY 4.0) license. Anyone may reproduce, distribute, translate and create derivative works of this article (for both commercial and non-commercial purposes), subject to full attribution to the original publication and authors. The full terms of this license may be seen

at: http://creativecommons.org/licences/by/4.0/legalcode

Vol. 10, No. 2, 2020, Pg. 401 - 411

Full Terms \& Conditions of access and use can be found at http://hrmars.com/index.php/pages/detail/publication-ethics 


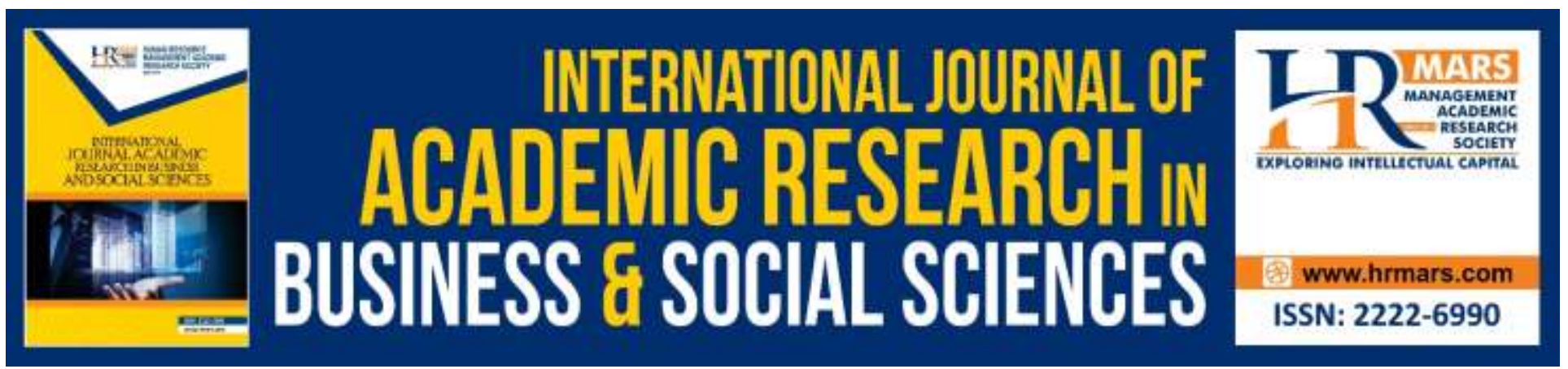

\title{
Elements of Gastronomy Tourism Affecting the Behavior of Thai Tourists Traveling in Thailand
}

\author{
Puri Chunkajorn \\ Culinary for Health Program, College of Integrative Medicine, Dhurakij Pundit University Bangkok, \\ Thailand
}

\begin{abstract}
The purpose of this research is to study the behavior of Thai tourists on food and to study the civilization and the elements of gastronomy tourism affecting the behavior of Thai tourists. The sample group used in this research is 400 Thai tourists. The variables in the study consists of the independent variables, namely personal factors such as gender, age, status, education level, occupation and average income per month, and the elements of food tourism and the dependent variable is the behavior of Thai tourists. Using statistical methods to find the frequency, percentage, mean, standard deviation, and use Chi-Square Test to analyze data at significance level 0.05.

The results of the research were as follows: 1 . Most of the sample groups had a convenient season to visit gastronomy tourism, ie November-December. The expected number of days for food tourism were 1-2 days. The source of food tourism information was Facebook. People who were travel buddies on gastronomy tourism for them were lovers / spouses. Travel method for food tourism was by using a personal car. The main purpose of traveling in food tourism was they loved a variety of local ingredients and the average cost of food tourism / people / meals was over 701 baht. 2.Demographic factors on gender, age, status and average income per month affected the behavior of Thai tourists on food. 3. Elements of gastronomy tourism that did not affect the behavior of Thai tourists with statistical significance at the level of 0.05
\end{abstract}

Keywords: Elements of Gastronomy Tourism, Behavior of Thai Tourists, Gastronomy Tourism

\section{Background and Importance of the Problem}

Tourism is an industry that plays an important role in the economic development of many countries around the world. The governments of each country in the country therefore place importance on enhancing their competitiveness in order to compete in the global travel market. In particular, countries in Asia and ASEAN draw more tourists from all over the world to travel in their own countries. Therefore, the tourism mission is a mission that is blended with the development of the country in all dimensions. Thus, the food tourism component is an important factor that helps attracting foreign tourists into gastronomy tourism and learn local culture from food. 
According to a report from the United Nations World Tourism Organization (UNWTO) about the global tourism situation, in 2015 , the number of international travelers continued to grow at a rate of 4 percent per year, totaling 810 million people. More than the same period last year by 33 million people. This is due to the continuous recovery of the European economy since the beginning of the year and the weakening of the euro. However, the Chinese tourist market still ranks number one with the expansion of the number of tourists traveling out of the country, resulting in Japan, Thailand, the United States of America. And many European tourist destinations have received benefits, as well as countries that emerge as emerging markets such as India, South Africa and Egypt that have reported high growth in tourism spending as well. (Office of the Permanent Secretary for Tourism and Sports, 2015.

However, spending on tourism of tourists is partly a cost of food. For some countries, therefore, focus on gastronomy Tourism, which is a tourism that combines the nature of the area, culture, service, access to tourist resources, being a good host and unique identity, combined with experience for tourists, especially the taste of food, learning how to make and cook, which is considered a impressive experience implantation to the tourists. In addition, gastronomy tourism is also distributing income to the local and agricultural sectors, both directly and indirectly, such as food that uses agricultural products as the main raw material, participation in learning and processing of agricultural products on farms, etc, including souvenir products about food such as spices, seasonings, finished food products, fruits, etc. (Prachachat Business Online, 2016)

However, bringing gastronomy tourism elements to create more experiences and impressions for tourists, both tourists, food and environment, will help encourage tourists to be interested in and participate in gastronomy tourism as well as remember more tourist attractions, so there should be a study and system to promote food tourism seriously. Therefore, the author wants to write this article to present the form of elements of gastronomy tourism that affect the behavior of Thai tourists traveling in Thailand that can be used in the development and promotion of gastronomy tourism efficiently at the national level, with the hope that this article will be useful to those who are concerned about and to those who are interested as well.

\section{Research Objectives}

1. To study the behavior of Thai tourists about food

2. To study demography that affects the behavior of Thai tourists on food

3. To study the elements of gastronomy tourism affecting the behavior of Thai tourists

\section{Research Hypothesis}

1. Demography affects the behavior of Thai tourists on food.

2. Elements of gastronomy tourism affect the behavior of Thai tourists related to food

\section{Conceptual Framework}

For the main conceptual framework used in research, the researcher studied the theories, concepts, research results and related documents on the issues of demographic theory, theories of consumer behavior, consumer behavior models, concepts of gastronomy tourism elements and related research. Therefore, the relationship between the independent variables and the dependent variables in the research are defined as follows: 
INTERNATIONAL JOURNAL OF ACADEMIC RESEARCH IN BUSINESS AND SOCIAL SCIENCES

Vol. 10, No. 2, Feb, 2020, E-ISSN: 2222-6990 @ 2020 HRMARS

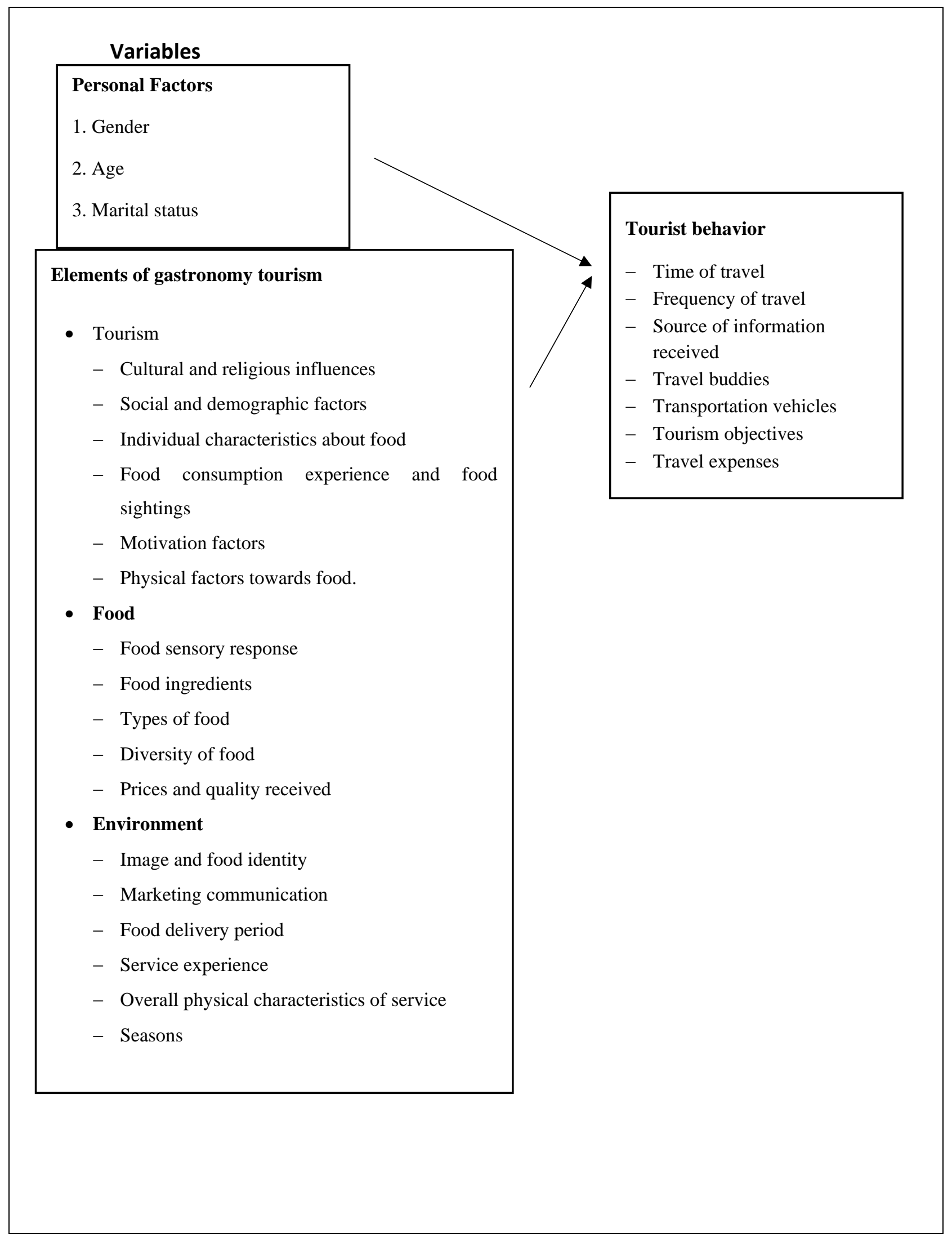


INTERNATIONAL JOURNAL OF ACADEMIC RESEARCH IN BUSINESS AND SOCIAL SCIENCES

Vol. 10, No. 2, Feb, 2020, E-ISSN: 2222-6990 ¿ 2020 HRMARS

\section{Population and Sample Group}

The population used in this research was Thai tourists traveling gastronomy tourism in Thailand.

As for the sample size in the selection of the sample used in this research, since the exact number of population was unknown, the researcher therefore used the calculation method from the formula of W.G. Cochran (1953). The size of the calculated sample was 384.16 samples. In order to reduce the error of the data, the researcher used a total of 400 samples.

\section{Research Tools}

The tools used in this research are questionnaires created from the study of concepts, theories of marketing mix, related research as a guideline for creating questionnaires by dividing into 3 parts:

Part 1: General information of respondents, including gender, age, status, education level, occupation and average income per month. There are 5 level of information measurement, which was characterized as a checklist and a closed-ended question.

Part 2 Information on elements of food tourism. The questionnaire is a closed question and positive questions. All the characteristics of the questionnaire are the rating scale questionnaire using Likert Scale method, which is a method of dividing the scale according to the opinion level into 5 criteria.

The questionnaire in this section will be used to measure the rating scale according to the Likert Scale (1932). The measure used to select the answer is 5 levels of importance (Chatchawan Ruengpraphan, 1996):

5 means strongly agree

4 means highly agree

3 means moderately agree

2 means less agree

1 means least agree

Part 3: Behavioral data of Thai tourists who come to food tourism. There are 7 items in a form of checklist and closed-ended questions.

\section{Data Collection}

The study of the elements of gastronomy tourism affecting the behavior of thai tourists this time, data collection is divided into 2 types:

\section{Primary Data}

The researcher collected data from the sample group by distributing the questionnaire to the sample group by selecting only Thai tourists who travel for gastronomy tourism in Thailand in order to allow the sample to be able to answer questions and express their opinions openly. The question line will relate to the reasons and factors related to the elements of food tourism that affect the behavior of Thai tourists.

\section{Secondary Data}

The researcher collected data from books, journals, theses, academic reports and related articles to review studies and researches on this issue. 
INTERNATIONAL JOURNAL OF ACADEMIC RESEARCH IN BUSINESS AND SOCIAL SCIENCES

Vol. 10, No. 2, Feb, 2020, E-ISSN: 2222-6990 @ 2020 HRMARS

\section{Data Analysis}

For data obtained from the collection, the researcher conducted the examination for the completion of questionnaire again and proceeded with the following steps.

1. Brought all selected questionnaires into serial numbers, in order from $001-400$

2. Created a code book

3. Brought all the information into code to analyze the data

4. Analyzed data using computer tools and software packages for social science research, helping to process data by statistical methods such as

4.1 The statistics used in analyzing the reliability of the statistical tool used was Cronbach's alpha coefficient. The reliability value of the whole questionnaire equal to 1 , indicating that this developed questionnaire was a questionnaire with high quality, both accuracy and content, due to it had the level of from 0.70 and up. In measuring the reliability of the questionnaire, the value was 0.886 which was greater than and equal to 0.70 . It can be concluded that the questionnaire was highly reliable.

4.2 Statistics used in general data analysis, basic data. Statistics used were frequency distribution and percentage

4.3 Analysis of the composition of food tourism. Statistics used were mean and standard deviation.

4.4 Statistic used to test hypotheses was Chi-Square which was used to test the relationship between 2 variables and compare the relationship between one variable and other variables in each, which in this research was about finding the relationship between the behavior of Thai tourists traveling on gastronomy tourism with personal factors and the elements of gastronomy tourism, which were used in the test with statistical significance equal to 0.05 .

5. Interpreted the meaning of the data according to the questions on an individual basis and in a whole way, by finding the average score of the rating divided into 5 levels (Chatchawan Ruangpraphan, 1996) according to the priorities that have on the factors as following:

The average of $4.50-5.00$ means that it is most important.

The average of $3.50-4.49$ means that it is important in a high level.

The average of $2.50-3.49$ means that it is important in the medium level.

The average of $1.50-2.49$ means that it is important in the low level.

The average of $1.00-1.49$ means that it is of the least importance.

\section{Conclusions}

Part 1: Results of personal factors analysis of the sample group showed that most of the sample groups were female, age 19-28 years, single status. Most of them graduated Bachelor's degree. Their occupation were civil servants / state enterprise employees with an average monthly income of 10,001-20,000 baht

Part 2: The results of the analysis of gastronomy tourism found that the overall food tourism factor had a high average score $(\bar{x}=4.12)$ and standard deviation was equal to (S.D. $=0.43)$. When considering each aspect, it was found that the tourism aspect had the highest mean score $(\bar{x}=4.21)$, followed by the environment $(\bar{x}=4.10)$, respectively. The aspect with the lowest average score was food $(\bar{x}=4.06)$. 
INTERNATIONAL JOURNAL OF ACADEMIC RESEARCH IN BUSINESS AND SOCIAL SCIENCES Vol. 10, No. 2, Feb, 2020, E-ISSN: 2222-6990 @ 2020 HRMARS

In terms of tourists, the overall average score was at a high level $(\bar{x}=4.21)$ and the standard deviation was equal to (S.D. $=0.42$ ) When considering each aspect, it was found that "You have motivation in food" had the highest average score $(\bar{x}=4.44)$, followed by "You think that the elements of culture and religion affect gastronomy tourism in the environment aspect" $(\bar{x}=4.33)$, "You think that different demographic and social factors affect gastronomy tourism decisions such as gender, age, education level, occupation" $(\bar{x}=4.21)$, "You are interested in the unique characteristics of food, such as the trend of food that has changed" ( $\bar{x}=4.15)$, "You think that physical factors affect food, such as hunger, thirst, and need" $(\bar{x}=4.08)$, respectively. The aspect with the lowest average score was "You have experienced in the consumption and sighting of local food" $(\bar{x}=4.07)$

In terms of food, the average score was at a high level $(\bar{x}=4.06)$ and the standard deviation was equal to (S.D. $=0.48$ ). When considering each aspect, it was found that Price and quality received of local food had the highest average score $(\bar{x}=4.26)$, followed by "You like the variety of food in each locality" ( $\bar{x}=4.19)$, "You need local food sensory responses such as flavor, texture of food" and "You are interested in the type of food that is influenced by foreigners in that locality" which has the same mean value $(\bar{x}=4.01)$, "You are interested in the differences of food seasonings of each locality" $(\bar{x}=$ 3.97), respectively. The aspect with the lowest average score was "You like the outstanding cooking method" ( $\bar{x}=3.95)$.

In terms of environment, the overall average score was at high level $(\bar{x}=4.10)$ and standard deviation was equal to (S.D. $=0.54)$. When considering each aspect, it was found that "Service quality is the most important" had the highest average score $(\bar{x}=4.18)$, followed by "the overall element of the place is important" $(\bar{x}=4.17)$, "the local season that you travel to gastronomy tourism is important $(\bar{x}=4.14)$, the image of the food of each locality is important" $(\bar{x}=4.07)$, "time / location / People who eat with you is important" $(\bar{x}=4.05)$, respectively. The aspect with the lowest average score was "Advertising, public relations / food activities are important" $(\bar{x}=4.00)$.

Part 3: Results of behavior analysis of Thai tourists in decision making on gastronomy tourism found that most samples had a convenient season to travel to gastronomy tourism in Thailand from November to December. The expected number of days for food tourism was 1-2 days. The main source of information about gastronomy tourism was Facebook. The travel buddies were mostly lovers/spouses. Most favorite way for traveling was by using a personal car. The main purpose of traveling in gastronomy tourism was that they liked a variety of local ingredients, local food, and the average cost of gastronomy tourism / people / meals was more than 701 baht.

\section{Part 4 Hypothesis Testing}

Hypothesis testing in demographic factors on gender, age, status and average income per month had a significant effect on Thai tourists' behavior on food at the level of 0.05 , and the elements of gastronomy tourism that did not affect the behavior of Thai tourists with statistical significance at the level of 0.05 , as shown in Table 1

Table 1, testing the relationship of personal factors and elements of gastronomy tourism and behavior of Thai tourists 
INTERNATIONAL JOURNAL OF ACADEMIC RESEARCH IN BUSINESS AND SOCIAL SCIENCES Vol. 10, No. 2, Feb, 2020, E-ISSN: 2222-6990 @ 2020 HRMARS

\begin{tabular}{|l|c|c|c|c|c|c|c|}
\hline \multicolumn{1}{|c|}{ Factors } & Gender & Age & $\begin{array}{c}\text { Marita } \\
\text { status }\end{array}$ & Education & $\begin{array}{c}\text { Occupat } \\
\text { ion }\end{array}$ & $\begin{array}{c}\text { Average } \\
\text { monthly } \\
\text { income }\end{array}$ & $\begin{array}{c}\text { Element } \\
\text { sof } \\
\text { gastron } \\
\text { omy } \\
\text { tourism }\end{array}$ \\
\hline Time of travel & $\checkmark$ & $\checkmark$ & $\checkmark$ & & & & \\
\hline Frequency of travel & & & & & & & \\
\hline $\begin{array}{l}\text { Source of } \\
\text { information }\end{array}$ & & & & & & & \\
\hline Travel companion & & & & & & & \\
\hline Tourism vehicle & $\checkmark$ & $\checkmark$ & $\checkmark$ & & & & \\
\hline Tourism purpose & $\checkmark$ & $\checkmark$ & $\checkmark$ & & & & \\
\hline Tourism expenses & & & & & & & \\
\hline
\end{tabular}

\section{Conclusion}

The study of gastronomy tourism factors affecting the behavior of Thai tourists had the following research objectives;

1. In terms of studying the behavior of Thai tourists on food, it was found that most samples had a convenient season to travel to gastronomy tourism in Thailand from November to December. The expected number of days for food tourism was 1-2 days. The main source of information about gastronomy tourism was Facebook. The travel buddies were mostly lovers/spouses. Most favorite way for traveling was by using a personal car. The main purpose of traveling in gastronomy tourism was that they liked a variety of local ingredients, local food, and the average cost of gastronomy tourism / people / meals was more than 701 baht. These were consistent with the research of Mr. Surasiranon (2011), the study of backpackers behavior in Chinese tourists to choose a restaurant In the Bangkok metropolitan area, it was found that the results of the study showed that Chinese tourists who were backpackers had given importance to factors of travel time and advice from friends and websites in choosing to go to restaurants in Bangkok. The least important factor was the distance to the airport and in addition, they also learned about the needs of different services with the culture of the Thai people, which were soup service and Chinese menu, because Chinese people loved to have hot soup as a side dish in each meal, which even when traveling, they still wanted to have a cup of soup. In terms of the Chinese menu, from the fieldwork, most Chinese people were not able to speak English very well, so the Chinese menu was also preferred for tourists.

2. In terms of studying demography that affects the behavior of Thai tourists on food, it was found that demographic factors in terms of gender, age, status and average income per month had an effect on the behavior of Thai tourists on food, which was consistent with Neranchara Kijwikranot's research (2014) on the image of Thai food, perceived Thai food quality and gastronomy tourism behavior trends of foreign tourists. The hypothesis testing found that foreign tourists who 
had different gender, travel objectives, travel times, would have a different trend of tourist behavior in the future with statistical significance, and foreign tourists with different age, nationality, occupation, income and education levels would not have a different trend of tourist behavior in the future with statistical significance. The image of Thai food was related to the trend of future tourists behavior, and the perception of Thai food quality was significantly related to the trend of tourist behavior in the future with statistical significance. Moreover, Kim et al. (2009 referred to in Mak et al., 2011, p. 8) found that gender, age and education were the three social variables and consumer characteristics that affected tourists who consumed local food. In the study, an interview was conducted. Most tourists who were women groups would be interested and excited about tasting local food on holiday. An interview with elderly tourists and those with higher education levels was also conducted and found that the consumption of local food of these two groups of tourists was very concerned about the health effects, but there was a desire to learn and experience with foreign culture through local food consumption.

3. In terms of studying the elements of gastronomy tourism affecting the behavior of Thai tourists, it was found that the elements of gastronomy tourism did not affect the behavior of Thai tourists at a statistical significance level of 0.05 , which was consistent with Mitchell \& Hall's research (2003). In the literature, there were reports that tourists enjoyed local food (Wagner, 2001). knowledge of local, regional and national food had become an interesting topic for tourists (Gallagher, 2001). In addition, there were reports that tourists were interested in cooking, which was an incentive for tourists to travel more, causing the food to have less potential (Bernard \& Zaragoza, 1999; Selwood, 2003) and did not take advantage of the convenience of the location to be a tourism resource which would not show the behavior of gastronomy tourism. Gastronomy tourism is not just an income generating activity, but also enhancing the effectiveness of cultural activities that are conducive to the tourism experience. Therefore, it needs to be considered as an important component of the marketing strategy of the tourist destination.

\section{Suggestions from the Research Results}

From the research results and data analysis as proposed above, about the elements of gastronomy tourism affecting the behavior of Thai tourists traveling on gastronomy tourism. Therefore, business owners and related persons can use this information for consideration in order to establish guidelines for creating a stimulus for food tourism marketing and the behavior of Thai tourists. The researcher has the following suggestions.

1. The elements of gastronomy tourism is very high. There should be a focus of customers who are ready to travel in each province, such as groups that are single or have careers that generate high income and are suitable for the behavior of being Thai, etc., since these factors can be considered affecting the behavior of Thai tourists.

2. As for the elements of gastronomy tourism that affects the behavior of Thai tourists, there should be a way to promote the market to have a widespread and easily accessible approach in order to increase the customer base. For this reason, therefore, the marketing should be promoted to become more known and more widely, since at present, there are more Thai tourists who come for gastronomy tourism in each province.

3. From the results of the study, it is found that the level of gastronomy tourism is very high, so it should be promoted and developed to be more attractive and interesting, as well as to improve 
INTERNATIONAL JOURNAL OF ACADEMIC RESEARCH IN BUSINESS AND SOCIAL SCIENCES

Vol. 10, No. 2, Feb, 2020, E-ISSN: 2222-6990 @ 2020 HRMARS

the image of gastronomy tourism continuously in order to maintain the original tourist base and increase the new tourist base. In that case, Thai tourists will be introducing and tell to others to visit.

\section{Suggestions for Future Research}

In the next research, the researcher should add studies on various issues as follows:

1. The next research should expand the sample group to other business groups.

2. There should be studies on other factors that are related to the behavior of Thai tourists traveling in gastronomy tourism according to each province such as communication, recognition of food information in each community which is expected to be an important part and is related to the behavior of Thai tourists.

3. This study focuses only on variables that are related to factors affecting the behavior of Thai tourists in accordance with the conceptual framework of just some variables according to the context of the research which does not have enough theory to support the international level. Moreover, most studies that are currently studied are quantitative studies, so the researchers think that there should be an in-depth study to know more about the factors that affect the behavior of Thai tourists by synthesizing from other concepts and theories that are consistent in the next order

4. There should be a study of the attitude and opinions of tourists towards gastronomy tourism in traveling.

5. There should be a study on the perception of food tourism with Thai and foreign tourists, to have a comparative study between tourists who first came and tourists returning to this tourist attraction again.

6. There should be a study of the satisfaction of various gastronomy tourism within each province's tourist destination. And in addition, the price for each product must be appropriate, worth in the finances of tourists.

\section{Research Limitations}

1. This research studied only Thai tourists traveling for gastronomy tourism in Thailand, which did not cover foreign tourists. The elements of gastronomy tourism and the behavior of Thai tourists according to each province may be different, so may not be able to apply such research results to all other provinces.

2. This research is limited to a study of specific elements of gastronomy tourism affecting Thai tourists' behavior, focusing on the elements of gastronomy tourism only, which does not cover other factors that may have a relationship or influence the behavior of Thai tourists. Therefore, there should be a study on the other factors that influence the behavior of Thai tourists traveling on gastronomy tourism in each province in order to use that factor as a guideline for improvement and create incentives as well as the development of tourism businesses in each province.

3. This research is only quantitative study, allowing to obtain information at a certain level which may not be very deep in some issues. Therefore, in the next research, studies should be conducted using qualitative research methods, collecting research data with interviews with Thai tourists and foreigners traveling for gastronomy tourism to gain more various opinions other than this research. 
INTERNATIONAL JOURNAL OF ACADEMIC RESEARCH IN BUSINESS AND SOCIAL SCIENCES

Vol. 10, No. 2, Feb, 2020, E-ISSN: 2222-6990 @ 2020 HRMARS

\section{Corresponding Author}

Mr.Puri Chunkajorn, College of Integrative Medicine, Dhurakij Pundit University Bangkok, Thailand Email: chefmungon@gmail.com

\section{References}

Surasiranon, P. (2011). Chinese tourists backpackers behavior on choosing restaurants in Bangkok. Department of Geography, Faculty of Arts, Chulalongkorn University.

Kijwikranot, N. (2007). The image of Thai food, perceived Thai food quality and gastronomy tourism behavior trends of foreign tourists. Academic Journal of International Thai Tourism, Year 10, Issue $1 / 2014$.

Ruengpraphan, C. (1996). Basic statistics. Khon Kaen: Klang Nana Witthaya Press. -

Bernard, A., and Zaragoza, I. (1999) Art and gastronomy routes: An unexplored tourism proposal for latin America. In First Pan-American Conference.

Cochran, W. G. (1953). Sampling Techiques. New York : John Wiley \& Sons. Inc.

Gallagher, B. (2001). The role of food and beverage in tourism. In Tourism as a catalyst for community development conference. Pretoria, South Africa: n.p

Hall, M., Mitchell, R. (2003), "Gastronomic tourism: comparing food and wine tourism experiences", in Novelli, M. (Eds), Niche Tourism. Contemporary Issues, Trends and Cases, Elsevier, Barking.

Kim, Y. G., Eves, A., Scarles, C. (2009). Building a model of local food consumption on trips and holidays: a grounded theory approach. International Journal of Hospitality Management, 28, 423-431.

Likert, Rensis, A. (1961). New Patterns of Management.New York: McGraw-Hill Book Company Inc.

Mak, A. H. N., Lumbers, M., Eves, A., Chang, R. C. Y. (2011). Factors influencing tourist food consumption. International Journal of Hospitality Management, 31, 928-936.

Selwood, J. (2003). The lure of food: Food as an attraction in destination marketing in Manitoba, Canada. In C.M. Hall, L. Sharples, R. Mitchell, N. Macionis and B.

Wagner, H. A. (2001). Marrying food and travel . . c culinary tourism. Canada's Food News, Foodservice Insights, March. 